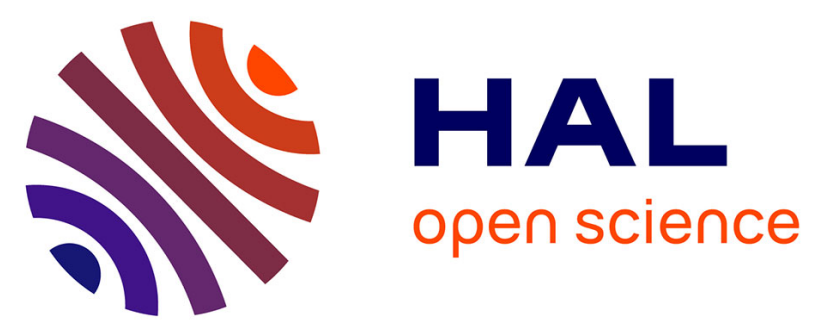

\title{
Outcomes of operative vaginal delivery managed by residents under supervision and attending obstetricians: a prospective cross-sectional study
}

Loïc Sentilhes, Hugo Madar, Guillaume Ducarme, Jean-François Hamel, Aurélien Mattuizzi, Matthieu Hanf

\section{To cite this version:}

Loïc Sentilhes, Hugo Madar, Guillaume Ducarme, Jean-François Hamel, Aurélien Mattuizzi, et al.. Outcomes of operative vaginal delivery managed by residents under supervision and attending obstetricians: a prospective cross-sectional study. American Journal of Obstetrics and Gynecology, 2019, 221, pp.59.e1 - 59.e15. 10.1016/j.ajog.2019.02.044 . hal-03484967

\section{HAL Id: hal-03484967 \\ https://hal.science/hal-03484967}

Submitted on 20 Dec 2021

HAL is a multi-disciplinary open access archive for the deposit and dissemination of scientific research documents, whether they are published or not. The documents may come from teaching and research institutions in France or abroad, or from public or private research centers.
L'archive ouverte pluridisciplinaire HAL, est destinée au dépôt et à la diffusion de documents scientifiques de niveau recherche, publiés ou non, émanant des établissements d'enseignement et de recherche français ou étrangers, des laboratoires publics ou privés.

\section{(c) (1) $\$$}

Distributed under a Creative Commons Attribution - NonCommerciall 4.0 International 


\section{Outcomes of operative vaginal delivery managed by residents under supervision and attending obstetricians: a prospective cross-sectional study}

Loïc Sentilhes MD, $\mathrm{PhD}^{1}$, Hugo Madar $\mathrm{MD}^{1}$, Guillaume Ducarme MD, $\mathrm{PhD}^{2}$, Jean-François Hamel, MD, $\mathrm{PhD}^{3}$, Aurélien Mattuizzi MDํ․ Matthieu Hanf, $\mathrm{PhD}^{4}$.

1. Department of Obstetrics and Gynecology. Bordeaux University Hospital, Bordeaux, France.

2. Department of Obstetrics and Gynecology, General Hospital, La Roche sur Yon, France;

3. Clinical Research Centre, Angers University Hospital, Angers, France;

4. Inserm CIC 1413, Nantes University Hospital, Nantes, France

\section{Corresponding author and reprint requests to:}

Loïc Sentilhes, M.D., Ph.D.

Department of Obstetrics and Gynecology

Bordeaux University Hospital,

Place Amélie Raba Léon, 33076 Bordeaux, France.

Tel: (33) 557821612 Fax: (33) $557821614 \quad$ E-Mail: loicsentilhes@ hotmail.com

Short Title: Morbidity after operative vaginal delivery

Financial disclosure: Loïc Sentilhes has conducted consultancy work and lectured for Ferring Laboratories in the past 3 years. The other authors report no potential conflicts of interest.

\section{Funding: None.}

Acknowledgments: We thank the women who participated in this study and the midwives and obstetricians involved in their care.

Presentation information: These findings were presented in part at the annual meeting of the Society of Maternal-Fetal Medicine; Dallas, January-February 29-3, 2018. 


\section{Condensation}

Management of attempted operative vaginal delivery by residents under supervision is not associated with more maternal or neonatal morbidity than management by attending obstetricians.

Short title: Operative vaginal delivery and residents

\section{AJOG at a Glance:}

\section{A. Why was this study conducted?}

This study was conducted to determine whether the maternal or neonatal outcome after an attempted operative vaginal delivery by residents under supervision is poorer than after such deliveries managed by attending obstetricians.

\section{B. What are the key findings?}

An attempted operative vaginal delivery managed by an obstetric resident under supervision was not associated with a higher rate of severe maternal and neonatal morbidity than such a delivery managed by an attending obstetrician.

\section{What does this study add to what is already known?}

These reassuring results support the continued use of residency programs to provide training for operative vaginal deliveries under the supervision of an attending obstetrician and may participate in a virtuous circle to prevent the ongoing demise of these valuable skills. 


\begin{abstract}
Background: To assess both severe maternal and neonatal mortality and morbidity after attempted operative vaginal deliveries by residents under supervision and by attending obstetricians.
\end{abstract}

Study design: Secondary analysis of a five-year prospective study with cross-sectional analysis including 2192 women with live singleton term fetuses in vertex presentation who underwent an attempted operative vaginal delivery in a tertiary care university hospital. Obstetricians who attempted or performed an operative vaginal delivery were classified into two groups according to their level of experience: attending obstetricians (who had 5 years or more of experience) and obstetric residents (who had less than 5 years of experience) under the supervision of an attending obstetrician.

We used multivariate logistic regression and propensity score methods to compare outcomes associated with attending obstetricians and obstetric residents. Severe maternal morbidity was defined as third- or fourth-degree perineal laceration, perineal hematoma, cervical laceration, extended uterine incision for cesareans, postpartum hemorrhage $>1500 \mathrm{ml}$, surgical hemostatic procedures, uterine artery embolization, blood transfusion, infection, thromboembolic events, admission to the intensive care unit, or maternal death; severe neonatal morbidity was defined as a 5-minute Apgar score $<7$, umbilical artery $\mathrm{pH}<7.00$, need for resuscitation or intubation, neonatal trauma, intraventricular hemorrhage $>$ grade 2 , neonatal intensive care unit admission for more than 24 hours, convulsions, sepsis, or neonatal death.

Results: High prepregnancy BMI, second-stage pushing phase longer than 30 minutes, high dose of oxytocin, manual rotation, persistent occiput posterior or transverse positions, operating room delivery, midpelvic delivery, forceps, and spatulas were significantly more 
frequent in deliveries managed by attending obstetricians than residents whereas a secondstage pushing phase longer than 30 minutes was significantly more frequent in deliveries managed by residents. The rate of severe maternal morbidity was $7.8 \%(115 / 1475)$ for residents versus $9.9 \%$ (48/484) for attending obstetricians; for severe neonatal morbidity, the rates were $8.3 \%(123 / 1475)$ versus $15.1 \%$ (73/484), respectively. In the univariate, multivariable, and sensitivity analyses, attempted operative vaginal delivery managed by a resident was significantly and inversely associated with severe neonatal but not maternal morbidity. After propensity score matching, delivery managed by a resident was not significantly associated with severe maternal morbidity (adjusted OR: $0.74,95 \%$ CI: 0.39 1.38) and was no longer associated with neonatal morbidity (adjusted OR: 0.51, 95\% CI: $0.25-1.04)$

Conclusions: Management of attempted operative vaginal deliveries by residents under the supervision of attending obstetricians, compared with by the attending obstetricians themselves, does not appear to be associated with either maternal or neonatal morbidity. These reassuring results support the continued use of residency programs for training in operative vaginal deliveries under the supervision of attending obstetricians.

Key words: operative vaginal delivery; residents, registrars, training, maternal and neonatal morbidity; forceps, vacuum, Kiwi OmniCup vacuum, Thierry's spatula. 


\section{Introduction}

Operative vaginal delivery remains a procedure used in daily practice in modern obstetrics, one which all residents should be experienced in or at least comfortable with at the end of their training. ${ }^{1-3}$ The goal of operative vaginal delivery is to expedite delivery when the second stage of labor is excessively prolonged and/or when immediate or potential fetal compromise is suspected, but if and only if the fetal head is engaged in the maternal pelvis. ${ }^{1-3}$ Nonetheless, even though the American College of Obstetricians and Gynecologists (ACOG) considers that "forceps and vacuum extractors have low risk of complications and are acceptable for operative vaginal delivery," they are associated with higher short-term maternal and neonatal morbidity than occurs with spontaneous vaginal delivery; this is especially true for forceps delivery. ${ }^{1-3}$ They may also be associated with greater short-term morbidity than cesareans in some circumstances, depending on indication, fetal head station, operative instrument, and procedure (rotational and/or sequential instrument use). ${ }^{4}$ They may also expose the obstetrician to greater litigation risk, ${ }^{5}$ particularly in cases of neonatal trauma or brachial plexus injury, ${ }^{6}$ for both of which operative vaginal delivery is a well-known risk factor. $^{7}$

Unsurprisingly, the rates of operative vaginal deliveries have dramatically decreased over the past two decades in some parts of the world. In the United States, they have fallen from nearly $10 \%$ in 1994 to $3 \%$ in $2014^{8}$ for both vacuum and forceps, ${ }^{9}$ even though ACOG and the Society for Maternal-Fetal Medicine now advocate increased use of operative vaginal delivery as a strategy for reducing cesarean rates. ${ }^{10}$ Some authors warn that forceps delivery is becoming a "species on the brink of extinction". ${ }^{9}$ Proposals to correct this situation include proactive faculty teaching of this skill, ${ }^{11}$ simulators, ${ }^{12}$ or both, combined with procedural training ${ }^{11}$ to change the trend and increase the ability of future attending obstetricians to use operative vaginal delivery. 
One issue related to these deliveries by residents, specifically to forceps training and the transfer of knowledge and skills in delivery rooms under the supervision of an attending obstetrician, is that the teacher is partially blinded to this procedure, does not really control the application of the forceps blade or the force used during traction, and does not see the manipulations performed inside the mother's body. Under the constraints inherent in stressful emergency situations, it is easy to understand that attending obstetricians may be risk averse and prefer to perform the operative vaginal delivery themselves, especially in cases of known maternal or fetal pathology such as overweight, fetal growth restriction (FGR), macrosomia, or previous cesarean. Consequently, one of the main impediments to the performance of operative vaginal deliveries during residency may be the potentially strong belief of attending obstetricians that such a delivery performed by residents rather than themselves may present a higher risk of maternal and/or neonatal morbidity, although this has never been demonstrated. It is unlikely that it ever will be demonstrated, because a randomized trial of this question will probably never be conducted, for obvious ethical reasons. Observational studies with prospective data collection and appropriate statistical methods are the best compromise between quality and feasibility to determine whether level of experience affects maternal and neonatal outcomes after this type of delivery.

Contrary to the USA, the operative vaginal delivery rate has remained unchanged in France since 1995, at around 12 to $14 \%,{ }^{13-14}$ as in many European countries. ${ }^{15}$ Similarly, the cesarean delivery rate has remained stable since 2003 at around $21 \% .{ }^{13-14}$ These data, taken together, indirectly indicate an ongoing policy of resident training in operative vaginal delivery in France. We aimed to determine maternal and neonatal morbidity according to the managing practitioner — obstetric resident or attending obstetrician — in a large French observational study of attempted operative vaginal deliveries that collected numerous details related to maternal and fetal condition, and clinical decision making. Propensity-score 
analysis was used to ensure the comparability of the study groups and to minimize selection bias. 


\section{Materials and Methods}

\section{Study design and patients}

This is a secondary cross-sectional analysis of data from a prospective study that took place from December 2008 to October 2013 at a French tertiary care university hospital with more than 4000 annual deliveries. Detailed information about the participating women and protocol has already been reported elsewhere. ${ }^{16-18}$ This prospective study was primarily designed to assess the effect of fetal head station on short- and mid-term maternal and neonatal morbidity after attempted operative vaginal delivery. ${ }^{16-18}$ The number of cases included in this prospective study determined the sample size of this secondary cross-sectional analysis.

This study included all women carrying a live singleton fetus at term $(\geq 37$ weeks of gestation) who underwent an attempted operative vaginal delivery, defined by the application of at least one blade for forceps or spatula, or a vacuum, regardless of its success. Exclusion criteria were multiple gestations, infants with FGR, defined as weighing less than the 10th percentile for gestational age on Hadlock curves, ${ }^{19-20}$ a known congenital anomaly, noncephalic presentation, and missing data for the exposure or adjustment variables (see below).

All women received information about our study and consented to the collection of their data. The Research Ethics Committee of the University of Angers, France, approved the study (No. 2008).

The decision to perform an operative vaginal delivery, the choice of instrument (forceps, Kiwi OmniCup vacuum, or Thierry's spatulas), and the place of delivery (operating room or not) were left to the attending obstetrician's discretion. Operative vaginal deliveries were performed by either the attending obstetrician or the obstetric resident under the supervision of an attending obstetrician, who was always present in the delivery room when a 
resident performed such a delivery. Moreover, attending physicians always chose the instrument used and determined whether they needed to check the instrument placement personally before traction. All women were offered epidural analgesia. The bladder was emptied by catheter before delivery. In accordance with French guidelines, ${ }^{3}$ ultrasound for assessment of the fetal head position (but not station) was possible in cases of doubts after clinical examination, at the attending obstetrician's discretion; and it was recommended that rotational forceps-assisted deliveries ( $>90^{\circ}$ rotation) be avoided: only vacuum instruments were recommended for rotation. In the case of a failed operative vaginal delivery, the same resident performed the cesarean under the supervision of the same attending obstetrician.

The medical records of women with an attempted operative vaginal delivery were assessed and discussed at the daily morning staff meeting. Attending obstetricians regularly reviewed with residents the ACOG classification of fetal head station, ${ }^{21}$ academic knowledge about operative vaginal delivery, and the French National College of Obstetricians and Gynecologists (CNGOF) clinical practice guidelines for this type of delivery. ${ }^{3,22}$ Indications for attempted operative vaginal delivery included nonreassuring scalp $\mathrm{pH}$ and fetal heart rate abnormalities (defined by any of prolonged deceleration, bradycardia, or decreased variability) ${ }^{23}$ and/or prolongation of the second-stage pushing phase resulting from inadequate expulsive efforts or failure to progress. ${ }^{3,22}$ All women underwent continuous fetal heart rate monitoring. Episiotomy was left to the practitioner's discretion. All episiotomies were mediolateral. A pediatrician examined the newborn in all cases within 2 hours after delivery.

The details of the procedures used to manage the labor as well as all clinical outcomes identified during the immediate postpartum period were prospectively collected by the midwife or obstetrician and pediatrician responsible for the delivery and the neonate. Other data were collected by a research assistant, independent of the local medical team, from a 
prospectively maintained database of women who underwent attempted (or completed) operative vaginal delivery. ${ }^{16-18}$

\section{Endpoints}

The primary and secondary endpoints were composite variables of severe short-term maternal and neonatal morbidity, respectively. Severe short-term maternal morbidity was defined by at least one of the following criteria: third- or fourth-degree perineal laceration, perineal hematoma, cervical laceration, extended uterine incision for cesareans, postpartum hemorrhage $>1500 \mathrm{ml}$ (blood loss was routinely assessed with a collector bag placed just

after birth), ${ }^{24,25}$ surgical hemostatic procedures, uterine artery embolization, blood transfusion, infection, thromboembolic events, admission to the intensive care unit, and maternal death. ${ }^{16}$

Severe neonatal morbidity was defined by at least one of the following criteria: 5minute Apgar score $<7$, umbilical artery $\mathrm{pH}<7.00$ (umbilical artery blood gas values were routinely measured), need for resuscitation or intubation, neonatal trauma, intraventricular hemorrhage > grade 2, neonatal intensive care unit admission for more than 24 hours, convulsions, sepsis, and neonatal death. ${ }^{16}$

\section{Exposure variable}

In this study, obstetricians who attempted or performed an operative vaginal delivery were classified into two groups according to their level of experience: attending obstetricians (who had 5 years or more of experience) and obstetric residents (who had less than 5 years of experience).

\section{Adjustment variables}

All variables that might influence an attending obstetrician's decision to allow a resident to perform the operative vaginal delivery were used as adjustment variables. Thus maternal and 
obstetrical characteristics used in this study as adjustment variables included maternal age ( $\leq$ 30 years or $>30$ years), prepregnancy body mass index (BMI) based on height and the first weight noted in the obstetric record (BMI $<25 \mathrm{~kg} / \mathrm{m}^{2}, 25$ to $<30 \mathrm{~kg} / \mathrm{m}^{2}$ or $\geq 30 \mathrm{~kg} / \mathrm{m}^{2}$ ), and parity (nulliparous/parous); history of each cesarean delivery, adverse events during previous deliveries (birth weight $>4000 \mathrm{~g}$, shoulder dystocia, episiotomy, operative vaginal delivery, or postpartum hemorrhage $>1500 \mathrm{ml}$, preeclampsia, gestational hypertension, or FGR); in this pregnancy, diabetes mellitus during pregnancy (preexisting or gestational), gestational weight gain (> $20 \mathrm{~kg} / \leq 20 \mathrm{~kg}$ ), prenatal suspicion of macrosomia (determined by fundal height measurement at delivery $>37 \mathrm{~cm}$ for all gestational ages, ultrasonographic fetal abdominal circumference $>$ 90th percentile for gestational age on Hadlock curves ${ }^{19-20}$ or both), gestational age at delivery (determined by craniocaudal length at a first-trimester ultrasound examination or by the date of the last menstrual period, a second or third trimester ultrasonogram, or both if the first-trimester ultrasonogram was not performed) ${ }^{26}$ categorized into < 39 weeks, 39 to 40 weeks and > 40 weeks, type of labor (spontaneous or induced by prostaglandins, amniotomy, or oxytocin), second-stage pushing phase, from the beginning of expulsive efforts to birth (> $30 \mathrm{~min} / \leq 30 \mathrm{~min}$ ), epidural analgesia, fetal head position at crowning (occiput posterior or anterior or transverse), indication for attempted operative vaginal delivery (nonreassuring FHR only, arrested progress only, or both), fetal head station, defined as the level of the leading bony point of the fetal head in centimeters at or below the level of maternal ischial spines $(0$ and $+1=$ midpelvic, +2 and $+3=$ low,+4 and $+5=$ outlet), ${ }^{21}$ and the instrument type (forceps, Kiwi OmniCup vacuum, Thierry's spatulas, or sequential use of instruments).

Statistical analysis

Continuous variables were described by their medians and interquartile ranges and compared between groups by a Wilcoxon test. Categorical variables were described by 
proportions and compared by chi-square tests. We used logistic regression models, with multiple adjustments, to estimate crude and adjusted associations between the obstetricians' experience and the composite variables of short-term severe maternal and neonatal morbidity.

Because attending obstetricians' decisions about whether they or the resident should manage the operative vaginal delivery were probably guided by the pregnancy and delivery characteristics rather than by chance, a sensitivity analysis using propensity scores was conducted to limit potential bias. A 1:1 matching algorithm ${ }^{27}$ was used within a caliper of 0.15 standard deviations of the logit of the propensity score to match patients based on maternal age, gestational weight gain, duration of second-stage pushing phase, and epidural use. Exact matching was also performed for parity, persistent occiput position, station at attempted delivery, instrument type, history of cesarean, episiotomy, prepregnancy BMI, suspicion of macrosomia, gestational age, induction of labor, indication for attempted operative vaginal delivery, birth weight, history of adverse events during previous deliveries, diabetes mellitus during pregnancy, and history of preeclampsia, pregnancy induced hypertension, or FGR. Imbalance after matching was checked. Odds ratios were calculated to quantify the association between the obstetrician's experience and the endpoints by using logistic regression fitted by generalized estimating equations to account for paired data. ${ }^{28}$

A second sensitivity analysis was performed with multiple imputation of missing data; ${ }^{29}$ it considered all adjustment variables, the two primary outcomes, and the obstetrician's training level. This imputation used a bootstrap + Expectation-Maximization algorithm as implemented in the Amelia R package and generated 20 independent imputed data sets. A multivariate model was estimated for each imputed data set. The resulting estimates were pooled according to the Rubin rule. ${ }^{2}$ 


\section{Results}

During the study period, the hospital had 19,786 deliveries: $15,836(80.0 \%)$ were vaginal, including 2153 (13.6\%) successful operative vaginal deliveries, and 3950 (20.0\%) were cesareans, including 39 ( $0.2 \%$ of all deliveries and $1 \%$ of all cesareans) after failed operative vaginal delivery. This study analyzed the 2192 deliveries with an attempted operative vaginal delivery, both the successes $(98.2 \%)$ and failures (1.8\%). Among these deliveries, however, the 28 twins ( $\mathrm{n}=14$ women) and 26 preterm ( $<37$ weeks) and 14 FGR infants were excluded. Moreover, 179 deliveries had missing data for the exposure variable $(n=26)$ and/or for the adjustment variables $(n=157)$. A more detailed description of the patterns in the missing data is given in supplementary materials (Appendix 1). Therefore, our final sample for the main analysis comprised 1959 births with an attempted operative vaginal delivery: 1475 were performed by obstetric residents and 484 by attending obstetricians (Figure 1).

Table 1 details the maternal and labor characteristics and maternal and neonatal outcomes according to the obstetricians' level of training. High prepregnancy BMI, secondstage pushing phase longer than 30 minutes, high dose of oxytocin, manual rotation, persistent occiput posterior or transverse positions, operating room delivery, midpelvic delivery, forceps, and spatulas were significantly more frequent in deliveries managed by attending obstetricians than residents whereas a second-stage pushing phase longer than 30 minutes was significantly more frequent in deliveries managed by residents.

The rate of severe maternal morbidity after attempted operative vaginal delivery was $7.8 \%(\mathrm{n}=115)$ for residents and $9.9 \%(\mathrm{n}=48)$ for attending obstetricians and did not differ significantly between the two groups (Table 1). Delivery managed by residents was not significantly associated with severe maternal morbidity in either the univariate analysis (Table 2) (crude odds ratio [OR]: $0.77,95 \%$ confidence interval $[\mathrm{CI}]: 0.54-1.09, P=.144$ ) or the 
multivariable logistic regression analysis, which was adjusted for potential confounders (adjusted OR: $0.94,95 \%$ CI: $0.63-1.39, P=.746$ ). The sensitivity analysis based on multiple imputation was consistent with this primary analysis (adjusted OR: 0.94, 95\% CI: 0.64-1.38) (Figure 2).

The rate of severe neonatal morbidity after attempted operative vaginal delivery was $8.3 \%(\mathrm{n}=123)$ for residents and $15.1 \%(\mathrm{n}=73)$ for attending obstetricians and differed significantly between the two groups $(\mathrm{P}<0.001)$ (Table 1 ). Delivery managed by obstetric residents was significantly and inversely associated with severe neonatal morbidity in the univariate (crude OR: $0.51,95 \%$ CI: $0.38-0.70, \mathrm{P}<0.001$ ) and the multivariable logistic regression analyses, the latter adjusted for potential confounders (adjusted OR: $0.56,95 \% \mathrm{CI}$ : $0.39-0.80, \mathrm{P}=0.001)$. The sensitivity analysis based on multiple imputation was consistent with this primary analysis (adjusted OR: 0.56, 95\% CI: 0.41-0.79) (Figure 2).

The propensity score matching process produced 458 cases that could be analyzed: 229 matched deliveries in each group, including $15.5 \%$ of the deliveries managed by residents and $47.3 \%$ of those managed by attending obstetricians. The two matched groups were well balanced for all the variables we studied (Table 3). After propensity score matching, delivery managed by obstetric residents was not significantly associated with severe maternal morbidity (adjusted OR: 0.74, 95\% CI: 0.39-1.38) and was no longer associated with severe neonatal morbidity (adjusted OR: $0.51,95 \%$ CI: 0.25-1.04). 


\section{Comment}

\section{Principal findings}

In our study, attempted operative vaginal deliveries managed by supervised obstetric residents were not associated with a higher rate of severe maternal and neonatal morbidity than such deliveries managed by attending obstetricians.

\section{Meaning of the findings/Clinical implications}

Our findings have potentially important implications. In a USA retrospective cohort study, Epstein et al previously demonstrated what seems intuitively obvious — that senior obstetricians' experience matters. As doctors gained years of experience, their maternal complication rates fell for vaginal, cesarean, and overall deliveries. ${ }^{30}$ It is thus easy to speculate that attending obstetricians may feel uncomfortable letting obstetric residents attempt to manage an operative vaginal delivery and may feel conflict between their responsibilities: toward the woman and child, who may be losing an opportunity for the best possible care, and toward the resident they are supposed to be training. The apparent divergence of our results and those of Epstein et al may be explained by a fundamental difference between these studies. In ours, residents were never alone to manage an attempted operative vaginal delivery; it was always performed under the supervision of the attending obstetrician in the delivery room. Moreover, the attending obstetrician was always the person who decided if operative vaginal delivery should be attempted and who should do it (and always the only person legally responsible under French law).

Thus, our study may have assessed the attending obstetricians' performance as medical educators, or even indirectly their clinical performance (although we can assume that their poorer performance is due to their choosing to manage the most difficult situations themselves), rather than the impact of level of experience on maternal and neonatal outcome. 
The key point, however, is that our study provides reassuring evidence that neither maternal nor neonatal morbidity is increased when attending obstetricians decide that maternal and obstetric conditions allow them to let residents attempt the operative vaginal delivery under their supervision. This important finding may encourage attending obstetricians to continue or resume participation in residency programs for training in operative vaginal deliveries.

Moreover, Epstein et al also demonstrated that initial skills matter: variation in the overall quality of future attending obstetricians is determined far more by their initial skills than by the number of deliveries they have managed. ${ }^{31}$ It is therefore essential that the initial performance and learning of obstetric residents should be the best possible so that the complications related to their future operative vaginal deliveries are as low as possible. ${ }^{31}$ Intuitively, one might expect that the more confident and comfortable these current residents feel in handling operative vaginal deliveries, the more they often they will use these skills when necessary as attending obstetricians in the future. This in turn should ensure that they maintain their skills in and acceptable rates of operative vaginal deliveries and thus lower cesarean rates. ${ }^{32}$ Our results may participate in a virtuous circle to prevent the ongoing demise of these valuable skills. ${ }^{8}$ Finally, as Asch et al reported, medical training programs play a determinant role in the complication rates of their residents' future patients. ${ }^{33}$ In France, including at the university where this study was conducted, there are no formal training programs for operative vaginal deliveries but only lectures; in particular, routine simulation training and a simulation-based curriculum for operative vaginal deliveries are in their early stages and not yet universally available. ${ }^{11}$ Nevertheless, French residency programs are successfully training residents, based on the medieval apprentice-journeyman-master training sequence, as recently demonstrated in a national prospective study related to twin deliveries. ${ }^{34}$ This point should be underlined, as it may contribute to our positive results. 


\section{Strengths and weaknesses}

Our study presents several strengths. First, the data, including numerous details relevant to maternal, obstetric, and clinical decision characteristics (which are often unavailable in large retrospective population-based studies), came from a large prospective study performed in a center with a policy of planned vaginal delivery, demonstrated indirectly by its rates of operative vaginal $(13.6 \%)$ and cesarean $(20 \%)$ deliveries, and a policy of teaching residents to manage operative vaginal deliveries (around $75 \%$ of attempted operative vaginal deliveries were performed by residents). Second, these data are robust: a collector bag was routinely used to estimate blood loss after delivery, all neonates were routinely examined by a qualified neonatologist after delivery, and previous results have been consistent with other wellestablished findings in the literature, in particular regarding short- and mid-term severe maternal morbidity and short-term neonatal morbidity after delivery with forceps or vacuum. ${ }^{16-18}$ Third, we studied all attempted operative vaginal deliveries, including those that failed, for their exclusion might mask a possible negative effect. Fourth, as in all observational studies, the main limitation of ours is uncontrolled confounders, particularly indication bias, as demonstrated in our univariate analysis: attending obstetricians attempted operative vaginal deliveries in the most difficult and risky conditions, and residents undertook less complicated deliveries involving women and babies at lower risk. Moreover, confounders may persist after multivariable analyses, ${ }^{35}$ as our results suggest: there is no plausible or biological explanation for the finding that severe neonatal morbidity is significantly inversely associated with delivery managed by an obstetric resident. To control for the indication bias, we performed propensity score analysis and made rigorous adjustments for confounding factors, specifically for 19 maternal and obstetric characteristics, to minimize the likelihood of incorrectly attributing any association to operative vaginal delivery managed by attending obstetricians. This allowed us to eliminate these potential persisting confounders. Fifth, 
operative vaginal deliveries were attempted only in compliance with the prerequisites specified in most guidelines. ${ }^{1-3,10,36}$ In particular, ultrasonography was used restrictively, limited to the cases where the provider had a doubt regarding the fetal head position after clinical examination, as no evidence has demonstrated that the routine use of ultrasonography before attempting operative vaginal delivery affects maternal or neonatal outcomes. ${ }^{3,22,36}$

Nevertheless, we must acknowledge some limitations. First, despite our careful statistical approaches, including sensitivity, multivariate, and propensity score analyses, hidden confounders that were unfortunately not recognized may still be present. It is undeniable that a randomized controlled trial would be the best study design to determine the impact of the level of training on maternal and neonatal outcomes after attempted operative vaginal delivery, but the feasibility and rationale of such a trial appears very doubtful. Second, no prespecified sample size for the endpoints of this secondary analysis was formally calculated. Due to the sample size of our propensity score analysis $(n=458)$, some might argue that it is underpowered. To quantify this problem, a post-hoc calculation determined that with a sample size of 458 patients, $8-15 \%$ of deliveries with adverse maternal or neonatal outcomes and around $75 \%$ of deliveries managed by residents, there would have been a power of $80 \%$ and an alpha risk of 0.05 , so that an $\mathrm{OR}>2$ would have been detected in univariate logistic regression. This result seems to confirm that our study was correctly powered to identify strong associations between the obstetrician training level and short-term neonatal or maternal outcomes. Third, the study reflects the experience of one tertiary university hospital that uses Thierry's spatulas extensively, and its results can be generalized only to maternity units with similar policies (policy of vaginal birth and proactive training of residents based on continuing close but slowly decreasing supervision by skilled obstetricians, senior supervising staff, daily morning staff meetings) and facilities (university referral center). Fourth, we must underline that maternal and labor characteristics in our study differed significantly according 
to the obstetricians' level of training. This finding indirectly suggests that attending obstetricians allowed the residents to perform the operative vaginal delivery under their supervision in selected and likely easier cases. Fifth, our results are limited to short-term maternal and neonatal morbidity.

\section{Conclusion with future research implications}

These limitations notwithstanding, attempted operative vaginal delivery managed by an obstetric resident under supervision was not associated in this study with a higher rate of severe maternal and neonatal morbidity than attempted operative vaginal delivery managed by an attending obstetrician. These reassuring results support the continued use of residency programs to provide training for operative vaginal deliveries under the supervision of an attending obstetrician. 


\section{Reference}

1. ACOG Practice Bulletin No. 154: Operative Vaginal Delivery. Obstet Gynecol 2015;126:e56-65.

2. Royal College of Obstetricians and Gynaecologists. Operative Vaginal delivery. Greentop Guidelines No.26. January 2011. Available at: https://www.rcog.org.uk/globalassets/documents/guidelines/gtg_26.pdf

3. Vayssière C, Beucher G, Dupuis $\mathrm{O}$, et al. Instrumental delivery: clinical practice guidelines from the French College of Gynaecologists and Obstetricians. Eur J Obstet Gynecol Reprod Biol 2011;159:43-8.

4. Muraca GM, Sabr Y, Lisonkova S, et al. Perinatal and maternal morbidity and mortality after attempted operative vaginal delivery at midpelvic station. CMAJ 2017189:E764E772.

5. Keriakos R, Sugumar S, Hilal N. Instrumental vaginal delivery--back to basics. J Obstet Gynaecol 2013;33:781-6.

6. Chauhan SP, Chang KW, Ankumah NE, Yang LJ. Neonatal brachial plexus palsy: obstetric factors associated with litigation. J Matern Fetal Neonatal Med 2017;30(20):2428-2432.

7. Sentilhes L, Sénat MV, Boulogne AI, et al. Shoulder dystocia: guidelines for clinical practice from the French College of Gynecologists and Obstetricians (CNGOF). Eur J Obstet Gynecol Reprod Biol 2016;203:156-61.

8. Dildy GA, Belfort MA, Clark SL. Obstetric Forceps: A Species on the Brink of Extinction. Obstet Gynecol. 2016;128:436-9.

9. Merriam AA, Ananth CV, Wright JD, Siddiq Z, D'Alton ME, Friedman AM. Trends in operative vaginal delivery, 2005-2013: a population-based study. BJOG 2017;124:13651372. 
10. Caughey AB, Cahill AG, Guise J-M, Rouse DJ. Safe prevention of the primary cesarean delivery. Am J Obstet Gynecol 2014;210:17-9.

11. Gossett DR, Gilchrist-Scott D, Wayne DB, Gerber SE. Simulation Training for ForcepsAssisted Vaginal Delivery and Rates of Maternal Perineal Trauma. Obstet Gynecol 2016;128:429-35.

12. Solt I, Jackson S, Moore T, Rotmensch S, Kim MJ. Teaching forceps: the impact of proactive faculty. Am J Obstet Gynecol 2011;204:448.e1-4.

13. Blondel B, Lelong N, Kermarrec M, Goffinet F. Trends in perinatal health in France from 1995 to 2010. Results from the French National Perinatal Surveys. J Gyn Obstet Biol Reprod 2012;41:e1-15.

14. Coulm B, Bonnet C, Blondel B. French national perinatal survey 2016. Situation in 2016 and trends since 2010; October 2017 [Access May 09, 2018]. http://www.europeristat.com/images/doc/NPHR/French_National_Perinatal_Survey_2016 .pdf (English version).

15. EURO-PERISTAT Project, SCPE, EUROCAT. European Perinatal Health Report: health and care of pregnant women and babies in Europe in 2010; 2013 [Access May 9. 2018] http://www.europeristat.com

16. Ducarme G, Hamel JF, Legendre G, Bouet PE, Vandenbroucke L, Sentilhes L. Maternal and neonatal morbidity after attempted operative vaginal delivery according to fetal head station. Obstet Gynecol 2015;126:521-9.

17. Ducarme G, Hamel JF, Brun S, Madar H, Merlot B, Sentilhes L. Pelvic floor disorders 6 months after attempted operative vaginal delivery according to the fetal head station. PLOS One 2016;11:e0168591. 
18. Ducarme G, Hamel JF, Brun S, Madar H, Coatleven F, Sentilhes L. Female and male sexual function and maternal postpartum depression 6 months after attempted operative vaginal delivery according to fetal head station. PLOS One 2017;12:e0178915.

19. Hadlock FP, Harrist RB, Sharman RS, Deter RL, Park SK. Estimation of fetal weight with the use of head, body, and femur measurements-a prospective study. Am J Obstet Gynecol 1985;151:333-7.

20. Vayssière C, Sentilhes L, Ego A, et al. Fetal Growth Restriction and Intrauterine Growth Restriction - Guidelines for clinical practice from the French College of Gynecologist and Obstetricians (CNGOF). Eur J Obstet Gynecol Reprod Biol 2015;193:10-18.

21. Obstetrics forceps. ACOG commitee opinion, no. 59. Washington, DC: American College of Obstetricians and Gynecologists, 1988.

22. Sentilhes L, Gillard P, Descamps P, Fournié A. Indications and prerequisites for operative vaginal delivery: when, how and where? J Gynecol Obstet Biol Reprod 2008;37 Suppl 8:S188-201.

23. American College of Obstetricians and Gynecologists. ACOG Practice Bulletin. Clinical Management Guidelines for Obstetrician-Gynecologists, Number 70, December 2005 (Replaces Practice Bulletin Number 62, May 2005). Intrapartum fetal heart rate monitoring. Obstet Gynecol 2005;106:1453-60.

24. Sentilhes L, Winer N, Azria E, et al ; for the Groupe de Recherche en Obstétrique et Gynécologie (GROG). Tranexamic acid for the prevention of blood loss after vaginal delivery: the TRAAP trial. N Engl J Med 2018;379:731-42.

25. Deneux-Tharaux C, Sentilhes L, Maillard F, et al. Effect of routine controlled cord traction as part of the active management of the third stage of labor on postpartum hemorrhage: multicentre randomised controlled trial (TRACOR). BMJ 2013;346:f1541. 
26. Vayssière C, Haumonte JB, Chantry A, et al. Prolonged and post-term pregnancies: guidelines for clinical practice from the French College of Gynecologists and Obstetricians (CNGOF). Eur J Obstet Gynecol Reprod Biol 2013;169:10-6.

27. Austin PC. A comparison of 12 algorithms for matching on the propensity score. Stat Med 2014;33:1057-69. doi:10.1002/sim.6004

28. Liang K-Y, Zeger SL. Longitudinal data analysis using generalized linear models. Biometrika 1986;73:13-22. doi:10.1093/biomet/73.1.13

29. Rubin DB, Schenker N. Multiple imputation in health-care databases: an overview and some applications. Stat Med 1991;10:585-98.

30. Epstein AJ, Srinivas SK, Nicholson S, Herrin J, Asch DA. Association between physicians'experience after training and maternal obstetrical outcomes: Cohort study. BMJ 2013;346:f1596.

31. Epstein AJ, Nicholson S, Asch DA. The Production of and Market for New Physicians' Skill. National Bureau of Economic Research working paper 18678. January 2013. http://www.nber.org/papers/w18678. Accessed May 19, 2018.

32. Asch DA, Nicholson S, Srinivas SK, Herrin J, Epstein AJ. How do you deliver a good obstetrician? Outcome-based evaluation of medical education. Acad Med 2014;89:24-6.

33. Asch DA, Nicholson S, Srinivas S, Herrin J, Epstein AJ. Evaluating obstetrical residency programs using patient outcomes. JAMA 2009;302:1277-1283.

34. Schmitz T, Korb D, Azria E, et al. Neonatal outcomes after management of non-cephalic second twin delivery by residents. Am J Obstet Gynecol;2018:S341.

35. Rosenbaum PR, Rubin DB. The central role of the propensity score in observational studies for causal effects. Biometrika1983;70:41-55.

36. Ghi T, Eggeb $\varnothing$ T, Lees C, et al. ISUOG Practice Guidelines: intrapartum ultrasound. Ultrasound Obstet Gynecol 2018; 52:128-139. 


\section{List of figures and tables}

Figure 1. Study flow chart.

Figure 2. Crude, adjusted, multiple imputation, and propensity score matching odds ratios (95\% confidence interval) for severe maternal and neonatal morbidity after attempted operative vaginal delivery according to the obstetrician's level of experience (reference: attending obstetrician).

Table 1. Maternal and labor characteristics and maternal and neonatal outcomes for operative vaginal deliveries, according to the obstetrician's level of experience $(n=1959)$.

Table 2. Univariate and multivariate analysis of severe maternal and neonatal morbidity after attempted operative vaginal delivery $(n=1959)$.

Table 3. Matched covariates before and after propensity score matching. Appendix. Number and percentage of missing data in the 2138 term singleton attempted operative vaginal deliveries. 
Figure 1: Study flow chart

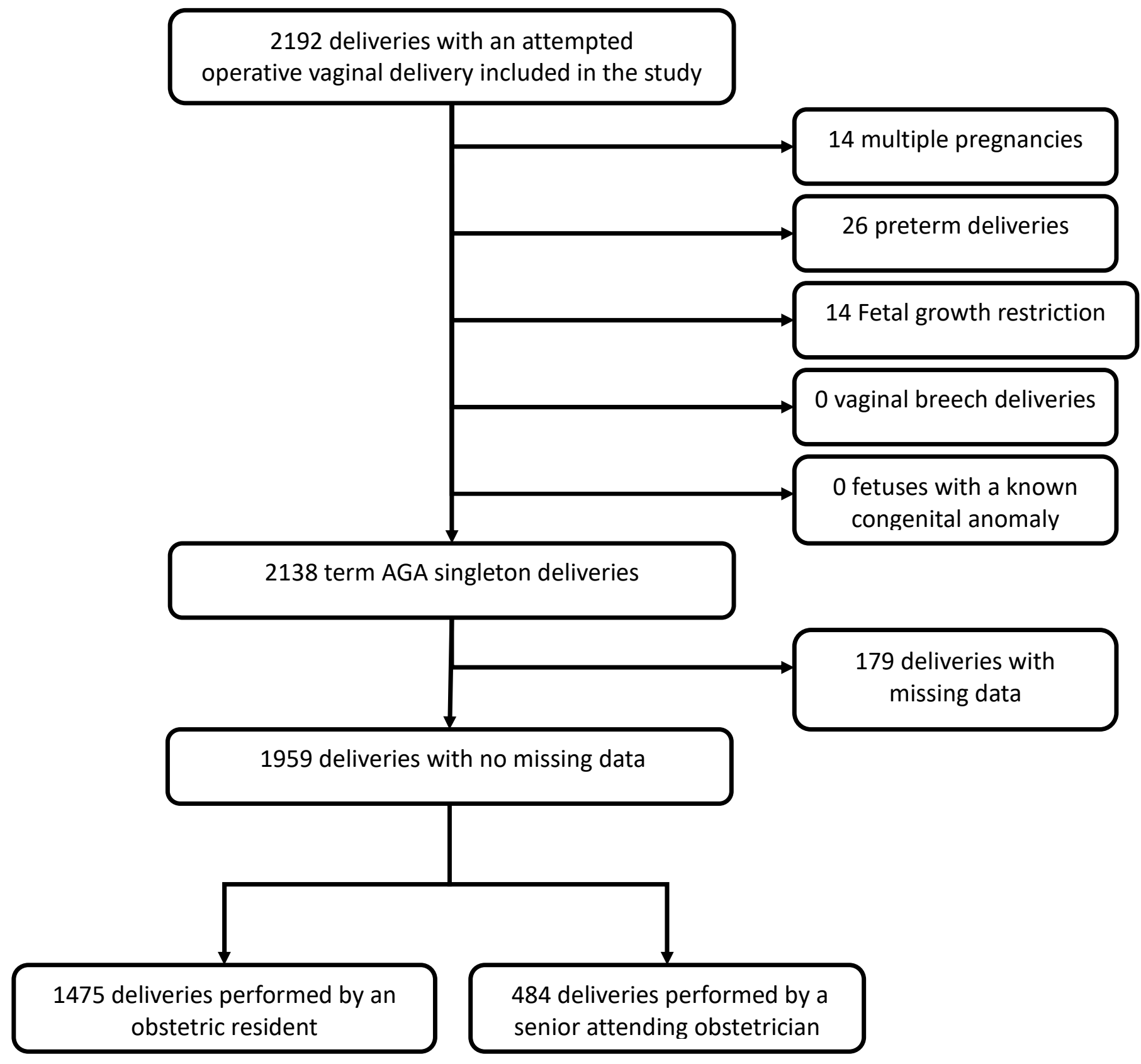


Figure 2: Crude, adjusted, multiple imputation, and propensity score matching odds ratios (95\% confidence interval) for severe maternal and neonatal morbidity after attempted operative vaginal delivery according to the obstetrician's level of experience (reference: attending obstetrician)

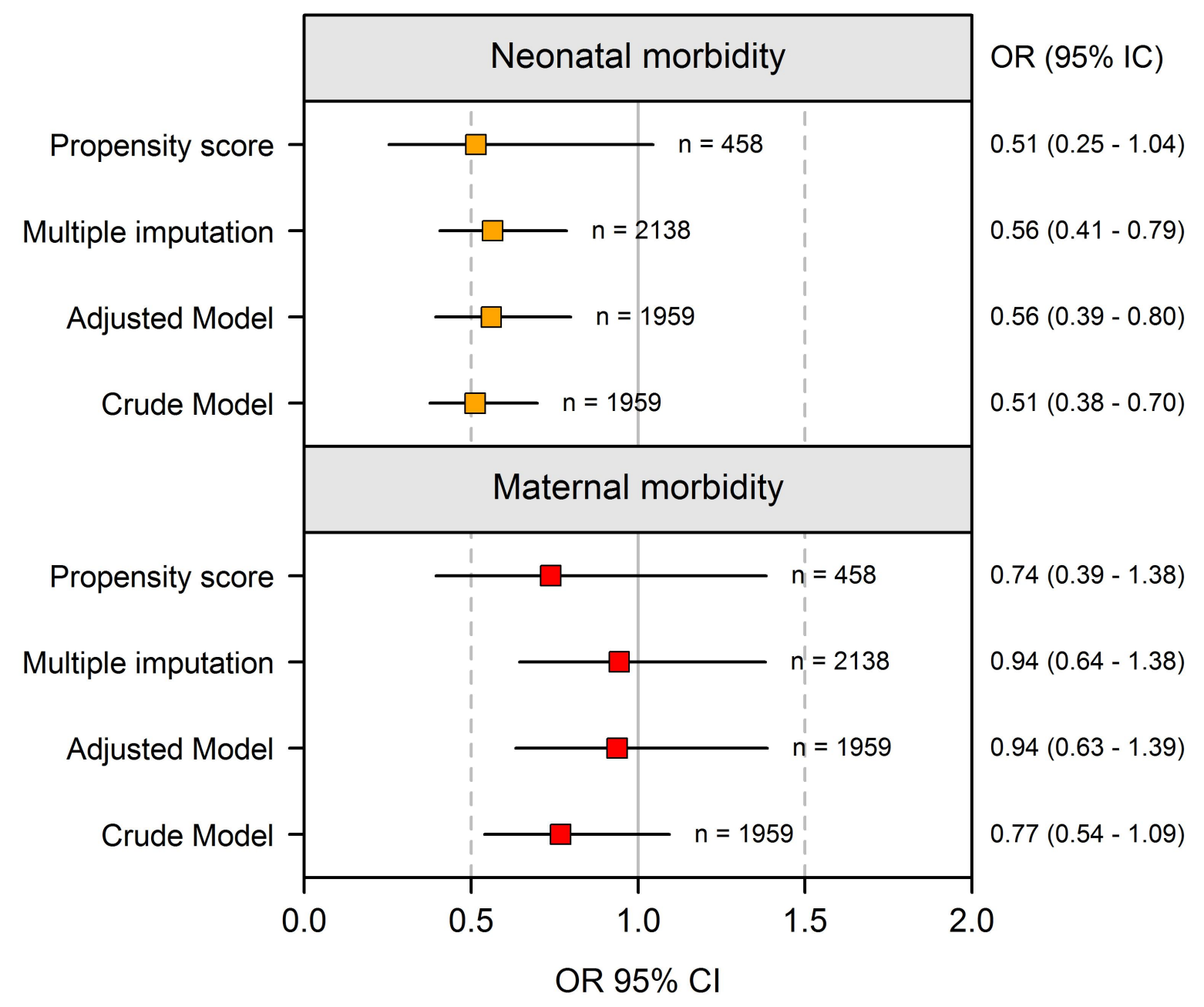

A 1:1 matching algorithm was used within a caliper of 0.15 standard deviations of the logit of the propensity score to match patients based on maternal age, gestational weight gain, duration of pushing phase of second stage, and epidural use. Exact matching was also performed for parity, persistent occiput position, station at attempted delivery, instrument type, history of cesarean delivery, episiotomy, prepregnancy BMI, suspicion of macrosomia, gestational age, induction of labor, indication for attempted operative vaginal delivery, birth weight, history of adverse events during previous deliveries (birth weight $>4000 \mathrm{~g}$, shoulder dystocia, episiotomy, operative vaginal delivery or postpartum hemorrhage), diabetes mellitus during pregnancy, and history of preeclampsia, pregnancy-induced hypertension or fetal growth restriction.

A bootstrap + Expectation-Maximization algorithm was carried out for multiple imputation: 20 independent imputed data sets were generated and a multivariate model was estimated for each. The resulting estimates were pooled according to the Rubin rule. 
Table 1. Maternal and labor characteristics and maternal and neonatal outcomes for operative vaginal deliveries, according to the obstetrician's level of experience $(n=1959)$

\begin{tabular}{|c|c|c|c|}
\hline Variables & $\begin{array}{l}\text { Obstetric } \\
\text { resident } \\
\mathrm{N}=1475\end{array}$ & $\begin{array}{c}\text { Attending } \\
\text { obstetrician } \\
\text { N= } 484\end{array}$ & $P$ value $\$$ \\
\hline \multicolumn{4}{|c|}{ Maternal and labor characteristics } \\
\hline Age (y) & $28(25,31)$ & $28(25,32)$ & 0.06 \\
\hline BMI before pregnancy (kg/m2) & $21.8(20.0,24.3)$ & $22.2(20.3,25.0)$ & 0.01 \\
\hline Nulliparity & $1099(74.5)$ & $358(74.0)$ & 0.86 \\
\hline Previous caesarean delivery & $151(10.2)$ & $54(11.2)$ & 0.63 \\
\hline Previous birth weight $>4000 \mathrm{~g}$ & $14(3.8)$ & $8(6.4)$ & 0.33 \\
\hline Gestational diabetes mellitus & $84(5.8)$ & $30(6.2)$ & 0.20 \\
\hline Prenatal suspicion of macrosomia* & $91(6.2)$ & $31(6.4)$ & 0.94 \\
\hline Gestational age at delivery (weeks) & $40(39,4)$ & $40(39,4)$ & 0.88 \\
\hline Induced labur & $257(17.4)$ & $92(19.0)$ & 0.47 \\
\hline Second stage longer than $3 \mathrm{~h}$ & $197(13.4)$ & 75 (15.5) & 0.27 \\
\hline Pushing phase of second stage longer than $30 \mathrm{~min}$ & $501(34.0)$ & $125(25.8)$ & 0.001 \\
\hline Dose of oxytocin (milli-international units) & $900(200,2260)$ & $1110(248,2620)$ & 0.04 \\
\hline Epidural analgesia & $1386(94.0)$ & $452(93.4)$ & 0.73 \\
\hline Manual rotation & $133(9.1)$ & $80(16.7)$ & $<0.001$ \\
\hline \multicolumn{4}{|l|}{ Persistent occiput } \\
\hline Anterior & $1324(89.8)$ & $403(83.3)$ & \\
\hline Posterior & $113(7.7)$ & $65(13.4)$ & $<0.001$ \\
\hline Transverse & $38(2.6)$ & $16(3.3)$ & \\
\hline \multicolumn{4}{|l|}{ Indication for operative vaginal delivery } \\
\hline Nonreassuring FHR only & $613(41.6)$ & $221(45.7)$ & \\
\hline Arrested progress only & $563(38.2)$ & 169 (34.9) & 0.27 \\
\hline Nonreassuring FHR and arrested progress & $299(20.3)$ & $94(19.4)$ & \\
\hline Operative vaginal delivery in OR & $2(0.1)$ & $30(6.2)$ & $<0.001$ \\
\hline \multicolumn{4}{|l|}{ Fetal head station } \\
\hline Outlet & $157(10.6)$ & $21(4.3)$ & \\
\hline Low & $1152(78.1)$ & 280 (57.9) & $<0.001$ \\
\hline Mid & $166(11.3)$ & $183(37.8)$ & \\
\hline \multicolumn{4}{|l|}{ Instrument type } \\
\hline Vacuum & 589 (39.9) & $87(18.0)$ & \\
\hline Forceps & $34(2.3)$ & 77 (15.9) & $<0.001$ \\
\hline Spatula & $904(61.3)$ & $345(71.3)$ & \\
\hline Sequential use of 2 instruments & $46(3.1)$ & $24(5.0)$ & 0.08 \\
\hline Rotational forceps delivery & $0(0.0)$ & $2(0.4)$ & 0.10 \\
\hline \multicolumn{4}{|c|}{ Maternal outcome } \\
\hline Caesarean delivery after failed operative vaginal delivery & $2(0.1)$ & $30(6.2)$ & $<0.001$ \\
\hline Extended uterine incision for caesarean delivery & $0(0.0)$ & $6(19.4)$ & 0.79 \\
\hline Episiotomy & 1296 (87.9) & $416(86.5)$ & 0.47 \\
\hline Third- or fourth-degree perineal laceration & $40(2.7)$ & $13(2.7)$ & 1 \\
\hline Perineal hematoma & $1(0.1)$ & $1(0.2)$ & 0.99 \\
\hline Manual removal of retained placenta & $164(19.8)$ & $82(28.4)$ & 0.003 \\
\hline Shoulder dystocia & $37(2.5)$ & $13(2.8)$ & 0.83 \\
\hline PPH (blood loss > $500 \mathrm{ml}$ ) & $232(15.7)$ & $98(20.3)$ & 0.02 \\
\hline Severe PPH (blood loss > 1500 ml) & $18(1.2)$ & $9(1.9)$ & 0.42 \\
\hline Need for an additional uterotonic agent & $27(3.3)$ & $13(4.5)$ & 0.43 \\
\hline Second-line therapies ${ }^{\dagger}$ & $4(0.5)$ & $2(0.7)$ & 1 \\
\hline Blood transfusion & $20(1.4)$ & $16(3.3)$ & 0.01 \\
\hline Infection ${ }^{\ddagger}$ & $19(1.3)$ & $8(1.7)$ & 0.71 \\
\hline Thromboembolic event & $3(0.2)$ & $1(0.2)$ & 1 \\
\hline Admission to ICU & $2(0.1)$ & $0(0.0)$ & 1 \\
\hline
\end{tabular}




\begin{tabular}{|c|c|c|c|}
\hline $\begin{array}{l}\text { Maternal death } \\
\text { Severe maternal morbidity }\end{array}$ & $\begin{array}{c}0(0.0) \\
115(7.8)\end{array}$ & $\begin{array}{l}0(0.00) \\
48(9.9)\end{array}$ & $\begin{array}{c}1 \\
0.17\end{array}$ \\
\hline \multicolumn{4}{|c|}{ Neonatal outcome } \\
\hline Birth weight $\geq 4000 \mathrm{~g}$ & $70(4.8)$ & $26(5.4)$ & 0.67 \\
\hline 5-min Apgar score $<7$ & $13(0.9)$ & $5(1.0)$ & 0.98 \\
\hline $\mathrm{pH}<7.00$ & $18(1.2)$ & $12(2.5)$ & 0.08 \\
\hline Transfer to NICU & $61(4.1)$ & $33(6.8)$ & 0.02 \\
\hline NICU hospitalization $>24 \mathrm{~h}$ & $58(3.9)$ & $32(6.6)$ & 0.02 \\
\hline Respiratory distress syndrome & 49 (3.3) & 19 (3.9) & 0.63 \\
\hline Scalp laceration & $66(4.5)$ & $42(8.7)$ & $<0.001$ \\
\hline Scalp hematoma & $20(1.4)$ & $26(5.4)$ & $<0.001$ \\
\hline Pain necessitating drugs & $134(9.1)$ & $65(13.5)$ & 0.01 \\
\hline Neonatal trauma ${ }^{k}$ & $8(0.5)$ & $4(0.8)$ & 0.72 \\
\hline Fracture of the clavicle & $4(0.3)$ & $2(0.4)$ & \\
\hline Fracture of a long bone & $0(0.0)$ & $0(0.00)$ & \\
\hline Brachial plexus injury & $4(0.3)$ & $2(0.4)$ & \\
\hline Cephalhematoma & $5(0.3)$ & $2(0.4)$ & \\
\hline Intraventricular hemorrhage > grade 2 & $0(0.0)$ & $0(0.00)$ & 1 \\
\hline Need for resuscitation or intubation & $8(0.5)$ & $1(0.2)$ & 0.57 \\
\hline Sepsis & $10(0.7)$ & 9 (1.9) & 0.04 \\
\hline Seizures & $4(0.3)$ & $0(0.0)$ & 0.57 \\
\hline Neonatal death & $0(0.0)$ & $0(0.00)$ & 1 \\
\hline Severe neonatal morbidity ^ & $123(8.3)$ & $73(15.1)$ & $<0.001$ \\
\hline
\end{tabular}

$\mathrm{BMI}$, body mass index; FHR, fetal heart rate; OR, operating room; PPH, postpartum hemorrhage; ICU, intensive care unit; NICU, neonatal intensive care unit.

Data are means (interquartile range) or $\mathrm{n}(\%)$ unless otherwise specified.

\$Categorical variables were compared with $\chi 2$ tests and continuous ones with Wilcoxon tests

* Prenatal suspicion of macrosomia: fundal height measurement at delivery $>37 \mathrm{~cm}$, ultrasonographic fetal abdominal circumference $>90$ th percentile for gestational age on Hadlock curves, or both.

${ }^{+}$Second-line therapies: uterine compression sutures, uterine artery embolization, and peripartum hysterectomy for management of massive primary postpartum hemorrhage after failure of uterine massage and uterotonic agents to stop bleeding.

₹ Infections were defined by at least one of the following: endometritis, episiotomy infection, or wound infection requiring surgery.

${ }^{\S}$ Severe maternal morbidity was defined by at least one of the following criteria: third- or fourthdegree perineal lacerations, perineal hematomas, cervical laceration, extended uterine incision at caesarean delivery, PPH $>1500 \mathrm{ml}$, surgical hemostatic procedure, uterine artery embolization, blood transfusion, infections (endometritis, episiotomy infection, wound infection requiring surgery), thromboembolic event (deep vein thrombophlebitis or pulmonary embolism), admission to intensive care unit, and maternal death.

${ }^{k}$ Neonatal trauma was defined by the existence of at least one of the following criteria: fracture of the clavicle or a long bone, brachial plexus injury, and cephalhematoma.

"Severe neonatal morbidity was defined by at least one of the following criteria: 5-min Apgar score < 7, umbilical artery $\mathrm{pH}<7.00$, need for resuscitation or intubation, neonatal trauma, intraventricular hemorrhage > grade 2, admission to the NICU > 24 hours, convulsions, sepsis, and neonatal death. 
Table 2. Univariate and multivariate analysis of severe maternal and neonatal morbidity after attempted operative vaginal delivery $(n=1959)$

\begin{tabular}{|c|c|c|c|c|c|c|c|c|c|}
\hline \multirow{2}{*}{\multicolumn{2}{|c|}{ Variable }} & \multicolumn{4}{|c|}{$\begin{array}{l}\text { Severe maternal morbidity } \\
\qquad(\mathrm{n}=1959)\end{array}$} & \multicolumn{4}{|c|}{$\begin{array}{l}\text { Severe neonatal morbidity } \\
\qquad(\mathrm{n}=1959)\end{array}$} \\
\hline & & \multirow{2}{*}{$\frac{\text { Crude OR }(95 \% \mathrm{Cl})}{1.00}$} & \multirow{2}{*}{$\begin{array}{l}P \\
-\end{array}$} & \multirow{3}{*}{$\begin{array}{c}\text { Adj. OR (95\% Cl) } \\
1.00 \\
1.02(0.70,1.48)\end{array}$} & \multirow{3}{*}{$\begin{array}{c}P \\
- \\
0.91 \\
\end{array}$} & \multirow{3}{*}{$\begin{array}{c}\text { Crude OR }(95 \% \mathrm{Cl}) \\
1.00 \\
0.83(0.5915)\end{array}$} & \multirow{3}{*}{$\begin{array}{c}\boldsymbol{P} \\
- \\
0.26\end{array}$} & \multirow{3}{*}{$\begin{array}{c}\text { Adj. OR (95\% Cl) } \\
1.00 \\
0.73(0.51,1.05)\end{array}$} & \multirow{3}{*}{$\frac{P}{-}$} \\
\hline Motomal ase & $\leq 30 y$ & & & & & & & & \\
\hline Maternal age & $>30 y$ & $1.07(0.76,1.51)$ & 0.71 & & & & & & \\
\hline BMI before pregnancy & $B M I(\mathrm{~kg} / \mathrm{m} 2)$ less than 30 & 1.00 & - & 1.00 & - & 1.00 & - & 1.00 & - \\
\hline & BMI 30 or higher & $1.22(0.67,2.22)$ & 0.51 & $1.30(0.70,2.41)$ & 0.40 & $1.90(1.17,3.08)$ & 0.01 & $1.70(1.02,2.84)$ & 0.04 \\
\hline \multirow{2}{*}{ Parity } & Multiparity & 1.00 & - & 1.00 & - & 1.00 & - & 1.00 & - \\
\hline & Nulliparity & $0.96(0.67,1.38)$ & 0.82 & $1.67(0.90,3.09)$ & 0.11 & $1.01(0.72,1.41)$ & 0.97 & $1.13(0.69,1.87)$ & 0.62 \\
\hline \multirow{2}{*}{ History of cesarean delivery } & No & 1.00 & - & 1.00 & - & 1.00 & - & 1.00 & - \\
\hline & Yes & $1.9(1.23,2.93)$ & 0.004 & $3.01(1.50,6.04)$ & 0.002 & $0.97(0.60,1.58)$ & 0.90 & $1.11(0.59,2.10)$ & 0.75 \\
\hline \multirow{2}{*}{ History of adverse events during delivery $\mu$} & No & 1.00 & - & 1.00 & - & 1.00 & - & 1.00 & - \\
\hline & Yes & $0.84(0.45,1.54)$ & 0.56 & $0.96(0.49,1.90)$ & 0.91 & $1.57(0.99,2.48)$ & 0.05 & $1.75(1.01,3.03)$ & 0.04 \\
\hline \multirow{2}{*}{$\begin{array}{l}\text { History of preeclampsia, pregnancy induced } \\
\text { hypertension, or fetal growth restriction }\end{array}$} & No & 1.00 & - & 1.00 & - & 1.00 & - & 1.00 & - \\
\hline & Yes & $1.18(0.53,2.61)$ & 0.69 & $1.32(0.57,3.07)$ & 0.52 & $1.45(0.73,2.88)$ & 0.29 & $1.09(0.52,2.28)$ & 0.82 \\
\hline \multirow{2}{*}{ Diabetes mellitus during pregnancy $f$} & No & 1.00 & - & 1.00 & - & 1.00 & - & 1.00 & - \\
\hline & Yes & $0.51(0.23,1.10)$ & 0.09 & $0.49(0.22,1.09)$ & 0.08 & $1.22(0.73,2.04)$ & 0.45 & $1.05(0.61,1.83)$ & 0.85 \\
\hline \multirow{2}{*}{ Gestational weight gain $>20 \mathrm{~kg}$} & No & 1.00 & - & 1.00 & - & 1.00 & - & 1.00 & - \\
\hline & Yes & $1.58(0.93,2.70)$ & 0.09 & $1.59(0.92,2.75)$ & 0.10 & $1.09(0.62,1.90)$ & 0.77 & $1.04(0.59,1.86)$ & 0.88 \\
\hline \multirow{2}{*}{ Prenatal suspicion of macrosomia† } & No & 1.00 & - & 1.00 & - & 1.00 & - & 1.00 & - \\
\hline & Yes & $1.74(1.00,3.01)$ & 0.05 & $1.69(0.95,3.01)$ & 0.07 & $0.98(0.53,1.81)$ & 0.95 & $0.91(0.48,1.73)$ & 0.77 \\
\hline \multirow{3}{*}{ Gestational age (weeks) } & Less than 39 weeks & $0.83(0.53,1.30)$ & 0.42 & $0.82(0.52,1.30)$ & 0.40 & $2.24(1.58,3.18)$ & $<0.001$ & $2.23(1.56,3.20)$ & $<0.001$ \\
\hline & 39 to 40 & 1.00 & - & 1.00 & - & 1.00 & - & 1.00 & - \\
\hline & Greater than 40 weeks & $1.4(0.97,2.02)$ & 0.07 & $1.45(0.98,2.15)$ & 0.06 & $1.37(0.95,1.99)$ & 0.10 & $1.26(0.85,1.87)$ & 0.26 \\
\hline \multirow{2}{*}{ Induced labor } & No & 1.00 & - & 1.00 & - & 1.00 & - & 1.00 & - \\
\hline & Yes & $1.04(0.69,1.58)$ & 0.84 & $0.89(0.56,1.41)$ & 0.62 & $1.58(1.11,2.23)$ & 0.01 & $1.40(0.94,2.08)$ & 0.09 \\
\hline \multirow{2}{*}{$\begin{array}{l}\text { Pushing phase of second stage longer than } 30 \\
\text { min }\end{array}$} & No & 1.00 & - & 1.00 & - & 1.00 & - & 1.00 & - \\
\hline & Yes & $1.2(0.77,1.86)$ & 0.43 & $1.04(0.65,1.68)$ & 0.86 & $0.68(0.42,1.10)$ & 0.12 & $0.60(0.35,1.00)$ & 0.05 \\
\hline \multirow{2}{*}{ Epidural analgesia } & No & 1.00 & - & 1.00 & - & 1.00 & - & 1.00 & - \\
\hline & Yes & $0.67(0.38,1.21)$ & 0.18 & $0.36(0.19,0.67)$ & 0.001 & $1.61(0.77,3.35)$ & 0.20 & $1.56(0.73,3.35)$ & 0.25 \\
\hline & Anterior & 1.00 & - & 1.00 & - & 1.00 & - & 1.00 & - \\
\hline Persistent occiput position & Posterior & $1.27(0.75,2.12)$ & 0.37 & $1.24(0.72,2.11)$ & 0.43 & $1.26(0.78,2.04)$ & 0.35 & $1.02(0.62,1.69)$ & 0.94 \\
\hline & Transverse & $0.90(0.32,2.53)$ & 0.84 & $0.92(0.32,2.63)$ & 0.87 & $1.88(0.90,3.92)$ & 0.10 & $1.63(0.76,3.49)$ & 0.21 \\
\hline & Nonreassuring FHR only & $0.65(0.45,0.93)$ & 0.02 & $0.66(0.45,0.98)$ & 0.04 & $1.06(0.75,1.50)$ & 0.75 & $0.94(0.65,1.37)$ & 0.74 \\
\hline $\begin{array}{l}\text { Indication for attempted operative vaginal } \\
\text { delivery }\end{array}$ & Arrested progress only & 1.00 & - & 1.00 & - & 1.00 & - & 1.00 & - \\
\hline & Nonreassuring FHR and arrested progress & $0.85(0.56,1.31)$ & 0.47 & $0.90(0.57,1.40)$ & 0.63 & $1.60(1.09,2.35)$ & 0.02 & $1.46(0.97,2.19)$ & 0.07 \\
\hline & Mid & $1.54(0.78,3.05)$ & 0.21 & $1.00(0.46,2.17)$ & 1 & $1.61(0.89,2.93)$ & 0.11 & $1.21(0.61,2.40)$ & 0.58 \\
\hline ACOG classification & Low & $1.22(0.66,2.26)$ & 0.53 & $0.93(0.48,1.82)$ & 0.83 & $1.03(0.60,1.77)$ & 0.92 & $0.94(0.52,1.68)$ & 0.82 \\
\hline & Outlet & 1.00 & - & 1.00 & - & 1.00 & - & 1.00 & - \\
\hline & Vacuum & 1.00 & - & 1.00 & - & 1.00 & - & 1.00 & - \\
\hline Instrument typ & Forceps & $2.38(1.19,4.78)$ & 0.01 & $2.52(1.16,5.46)$ & 0.02 & $2.26(1.26,4.04)$ & 0.006 & $1.44(0.75,2.78)$ & 0.27 \\
\hline motrument type & Spatula & $1.87(1.25,2.79)$ & 0.002 & $1.98(1.25,3.15)$ & 0.004 & $1.11(0.79,1.56)$ & 0.55 & $0.90(0.61,1.32)$ & 0.58 \\
\hline & Sequential use of instruments & $1.66(0.67,4.10)$ & 0.28 & $1.75(0.69,4.45)$ & 0.24 & $1.94(0.96,3.91)$ & 0.06 & $1.56(0.74,3.29)$ & 0.24 \\
\hline Jevel of experienc & Attending obstetrician & 1.00 & - & 1.00 & - & 1.00 & - & 1.00 & - \\
\hline Lever or experience & Obstetric resident & $0.77(0.54,1.09)$ & 0.14 & $0.94(0.63,1.39)$ & 0.75 & $0.51(0.38,0.70)$ & $<0.001$ & $0.56(0.39,0.80)$ & 0.001 \\
\hline
\end{tabular}

Unadjusted and adjusted logistic regression analyses. All the variables in the table were incorporated in the multivariable logistic models. OR: Odds ratio; $\mathrm{Cl}$ : confidence interval; PIH: pregnancy induced hypertension; FHR: fetal heart rate

$\mu$ : History of birth weight more than $4000 \mathrm{~g}$, shoulder dystocia, third or fourth perineal laceration, operative vaginal delivery or postpartum hemorrhage

$\mathrm{f}$ : Pre-existing or gestational diabetes mellitus 
Table 3. Matched covariates before and after propensity score matching

\begin{tabular}{|c|c|c|c|c|c|c|c|}
\hline \multirow{2}{*}{\multicolumn{2}{|c|}{ Variable \$ }} & \multicolumn{3}{|c|}{ Overall cohort $(\mathrm{n}=1959)$} & \multicolumn{3}{|c|}{ matched cohort $(n=458)$} \\
\hline & & $\begin{array}{l}\text { Obstetric } \\
\text { resident }\end{array}$ & $\begin{array}{l}\text { Attending } \\
\text { obstetrician }\end{array}$ & $\begin{array}{c}\text { Sd. } \\
\text { difference, \% }\end{array}$ & $\begin{array}{r}\text { Obstetric } \\
\text { resident }\end{array}$ & $\begin{array}{l}\text { Attending } \\
\text { obstetrician }\end{array}$ & $\begin{array}{c}\text { Sd. } \\
\text { difference, \% }\end{array}$ \\
\hline \multirow{2}{*}{ Maternal age $>30 y$} & No & 1054 (71) & $317(65)$ & 13 & $171(75)$ & $174(76)$ & 3 \\
\hline & Yes & $421(29)$ & $167(35)$ & 13 & $58(25)$ & $55(24)$ & 3 \\
\hline \multirow{2}{*}{ BMI before pregnancy } & $B M I\left(\mathrm{~kg} / \mathrm{m}^{2}\right)<25$ & $1378(93)$ & 449 (93) & 2.6 & 227 (99) & $227(99)$ & 0 \\
\hline & $B M I\left(\mathrm{~kg} / \mathrm{m}^{2}\right) \geq 25$ & $97(7)$ & $35(7)$ & 2.6 & $2(1)$ & $2(1)$ & 0 \\
\hline \multirow{2}{*}{ Parity } & Parity & $376(25)$ & $126(26)$ & 1.2 & $33(14)$ & $33(14)$ & 0 \\
\hline & Nulliparity & $1099(75)$ & $358(74)$ & 1.2 & $196(86)$ & $196(86)$ & 0 \\
\hline \multirow{2}{*}{ History of cesarean section } & No & $1324(90)$ & $430(89)$ & 3 & 214 (93) & $214(93)$ & 0 \\
\hline & Yes & $151(10)$ & $54(11)$ & 3 & $15(7)$ & $15(7)$ & 0 \\
\hline \multirow{2}{*}{ History of adverse events during delivery ${ }^{\mu}$} & No & 1357 (92) & $434(90)$ & 8.3 & $222(97)$ & $222(97)$ & 0 \\
\hline & Yes & $118(8)$ & $50(10)$ & 8.3 & $7(3)$ & $7(3)$ & 0 \\
\hline \multirow{2}{*}{$\begin{array}{l}\text { History of preeclampsia, pregnancy induced } \\
\text { hypertension, or fetal growth restriction }\end{array}$} & No & $1423(96)$ & $463(96)$ & 4.3 & $228(100)$ & $228(100)$ & 0 \\
\hline & Yes & $52(4)$ & $21(4)$ & 4.3 & $1(0)$ & $1(0)$ & 0 \\
\hline \multirow{2}{*}{ Diabetes mellitus during pregnancy $\mathrm{f}$} & No & $1357(92)$ & 449 (93) & 2.9 & $225(98)$ & $225(98)$ & 0 \\
\hline & Yes & $118(8)$ & $35(7)$ & 2.9 & $4(2)$ & $4(2)$ & 0 \\
\hline \multirow{2}{*}{ Gestational weight gain > $20 \mathrm{~kg}$} & No & 1371 (93) & $448(93)$ & 1.5 & $219(96)$ & $216(94)$ & 6 \\
\hline & Yes & $104(7)$ & $36(7)$ & 1.5 & $10(4)$ & $13(6)$ & 6 \\
\hline \multirow{2}{*}{ Prenatal suspicion of macrosomia ${ }^{\dagger}$} & No & 1384 (94) & $453(94)$ & 1 & $225(98)$ & $225(98)$ & 0 \\
\hline & Yes & $91(6)$ & $31(6)$ & 1 & $4(2)$ & $4(2)$ & 0 \\
\hline \multirow{3}{*}{ Gestational age (weeks) } & Less than 39 weeks & $306(21)$ & $99(20)$ & 0.7 & $43(19)$ & $43(19)$ & 0 \\
\hline & 39 to less than 41 & $819(56)$ & $269(56)$ & 0.1 & $142(62)$ & $142(62)$ & 0 \\
\hline & Greater than 41 & $350(24)$ & $116(24)$ & 0.6 & 44 (19) & 44 (19) & 0 \\
\hline \multirow{2}{*}{ Induced labor } & No & $1218(83)$ & $392(81)$ & 4.1 & $212(93)$ & $212(93)$ & 0 \\
\hline & Yes & $257(17)$ & $92(19)$ & 4.1 & $17(7)$ & $17(7)$ & 0 \\
\hline \multirow{2}{*}{$\begin{array}{l}\text { Pushing phase of second stage longer than } 30 \\
\text { min }\end{array}$} & No & $1278(87)$ & $409(85)$ & 6.2 & $209(91)$ & $206(90)$ & 4.5 \\
\hline & Yes & $197(13)$ & $75(15)$ & 6.2 & $20(9)$ & $23(10)$ & 4.5 \\
\hline \multirow{2}{*}{ Epidural analgesia } & No & $89(6)$ & $32(7)$ & 2.4 & $8(3)$ & $8(3)$ & 0 \\
\hline & Yes & 1386 (94) & $452(93)$ & 2.4 & $221(97)$ & $221(97)$ & 0 \\
\hline \multirow{3}{*}{ Persistent occiput position } & Anterior & $1324(90)$ & $403(83)$ & 20.1 & $210(92)$ & $210(92)$ & 0 \\
\hline & Posterior & $113(8)$ & $65(13)$ & 20.1 & $16(7)$ & $16(7)$ & 0 \\
\hline & Transverse & $38(3)$ & $16(3)$ & 4.5 & $3(1)$ & $3(1)$ & 0 \\
\hline \multirow{3}{*}{$\begin{array}{l}\text { Indication for attempted operative vaginal } \\
\text { delivery }\end{array}$} & Non-reassuring FHR only & $613(42)$ & $221(46)$ & 8.3 & $111(48)$ & $111(48)$ & 0 \\
\hline & Arrested progress only & $563(38)$ & $169(35)$ & 6.7 & $82(36)$ & $82(36)$ & 0 \\
\hline & Non-reassuring FHR and arrested progress & $299(20)$ & $94(19)$ & 2.1 & $36(16)$ & $36(16)$ & 0 \\
\hline \multirow{3}{*}{ ACOG classification } & Mid & $166(11)$ & $183(38)$ & 69.4 & $50(22)$ & $50(22)$ & 0 \\
\hline & Low & $1152(78)$ & $280(58)$ & 45.7 & $174(76)$ & $174(76)$ & 0 \\
\hline & Outlet & $157(11)$ & $21(4)$ & 21.9 & $5(2)$ & $5(2)$ & 0 \\
\hline \multirow{3}{*}{ Instrument type } & Vacuum & $548(37)$ & $68(14)$ & 49.8 & $36(16)$ & $36(16)$ & 0 \\
\hline & Forceps/spatula & $881(60)$ & $392(81)$ & 44.6 & $188(82)$ & $188(82)$ & 0 \\
\hline & Sequential use of instruments & $46(3)$ & $24(5)$ & 9.9 & $5(2)$ & $5(2)$ & 0 \\
\hline
\end{tabular}

н: History of birth weight more than $4000 \mathrm{~g}$, shoulder dystocia, episiotomy, operative vaginal delivery or postpartum hemorrhage

f: Pre-existing or gestational diabetes mellitus 